\title{
Lessons of Reproductive Ethics for Principlism
}

\author{
Morten Dige
}

Department of Philosophy and History of Ideas, Aarhus University, filmd@cas.au.dk

DOI: http://dx.doi.org/10.5324/eip.v13i1.2726

This is an open access article distributed under the terms of the Creative Commons
Attribution 4.0 International License, which permits unrestricted use, distribution, and
reproduction in any medium, provided the original author and source are credited.

This article brings together two debates in bioethics more substantively than has been the case until now. One is the methodological debate over "principlism," i.e., the theoretical framework for analyzing and solving (bio)ethical problems proposed by Beauchamp and Childress in Principles of Biomedical Ethics (PBE). The other is the normative debate about reproductive ethics, i.e., procreative rights and obligations in a time of pervasive opportunities for making detailed choices about the properties and capacities of future people. The obvious point of bringing the debates together is to show how they can illuminate each other in fruitful ways consistent with the method of reflective equilibrium endorsed in PBE. Furthermore, discussions of reproductive ethics is almost absent in PBE, making it an interesting "test case" on how principlist theory can have an impact on and be affected by confrontations with new practices and considerations in biomedicine. Reproductive ethics is especially interesting due to the so-called non-identity considerations, which pose a challenge to common morality views on harm to and respect for persons. My focus is mainly on some methodological points about the import of concrete normative discussions for formulating basic normative principles. However, I unfold a number of substantial points in order to demonstrate this. It is my impression that most writers on principlism underestimate the effect of engaging with concrete problems. Specifically, I conclude that reflecting on procreative obligations provides strong reasons for specifying the basic principles in ways that uncover new dimensions of them and not just new applications.

Keywords: principlism, reproductive ethics, non-identity problem, nonmaleficence, respect for persons

\section{Principles and principlism}

Principles of Biomedical Ethics by Tom Beauchamp \& James Childress (PBE in the following) is undoubtedly the most influential work in bioethics, and arguably in practical ethics more broadly. It has undergone quite substantial revisions from the first edition in 1979 to the seventh in 2013. The set of basic principles, however, has remained stable through all editions: 
(1) respect for autonomy (a norm of respecting and supporting autonomous decisions), (2) nonmaleficence (a norm of avoiding the causation of harm), (3) beneficence (a group of norms pertaining to relieving, lessening, or preventing harm and providing benefits and balancing benefits against risks and costs), and (4) justice (a group of norms for fairly distributing benefits, risks, and costs) (Beauchamp \& Childress 2013: 13).

The $P B E$ approach has been dominant to the extent that it is often equated with "principlism" or the principle-based approach. There are competing accounts, however, notably the set of principles developed by Bernard Gert and his co-authors (Clouser, Culver \& Gert 2006) and the (so-called) "European" principles developed by Rendtorff and Kemp (Rendtorff \& Kemp 2000). Thus, on the face of it, the four principles just listed are not necessarily definitive, and it is in many ways both illuminating and indeed required by the method of reflective equilibrium to challenge the $P B E$ set by comparing it with alternative accounts. For purposes of the discussion to come, I will restrict myself to a brief comparison with and discussion of a very similar but nonetheless importantly different set of principles, namely the principles stated in The Belmont Report (BR in the following) on the protection of human research subjects from 1978. The report was a reaction to a strongly felt need for protection of human research subjects made most vivid by the scandal surrounding the Tuskegee Study of Untreated Syphilis in the Negro Male. The study involved hundreds of impoverished black Alabama citizens suffering from syphilis who were deliberately not treated and not informed about their condition in order to study the "natural" progression of the disease. When the scandal finally broke in 1972 after forty years, numerous men had died of syphilis, 40 wives had contracted the disease, and 19 children had been born with congenital syphilis (Wikipedia).

The report established three ethical principles for the protection of human research subjects: (1) respect for persons, (2) beneficence, and (3) justice. Unlike the $P B E$ set, there is no independent principle of nonmaleficence, and respect for autonomy is replaced by a (seemingly broader) principle of respect for persons.

Tom Beauchamp served as a member of the professional staff of the committee behind the report and it is tempting to see it as a "prequel" to $P B E$, in which the more developed set of principles is stated. The truth is, however, that $B R$ and $P B E$ were worked out simultaneously and just had different publication speeds (Beauchamp 2010). A better explanation of the difference is that Beauchamp entered the committee at a stage where decisions about the basic principles had already been made. Thus, it is fair to see them as an alternative, and not just a less developed, set. I think the establishment of nonmaleficence as a freestanding principle is a change for the better even though the dividing line between beneficence and nonmaleficence is open for debate. The reduction of the principle of respect for persons to respect for autonomy is not as substantial as it may look but nonetheless a suitable opportunity for critical reflections. In the following, I present some of the reasons for these two points of critique. Later, I will show how they illuminate some of the important controversies in reproductive ethics.

\section{The division between beneficence and nonmaleficence}

Reasons of nonmaleficence are not absent in $B R$ but they are subsumed under the principle of beneficence. The report states the following: 
Two general rules have been formulated as complementary expressions of beneficent actions in this sense: (1) do not harm and (2) maximize possible benefits and minimize possible harms. (National Commission 1978, p. 6, emphasis mine)

Even so, the absence of the principle of nonmaleficence as a freestanding principle is striking. In the Tuskegee study, it seems natural to say that the primary wrong, morally speaking, was that people were harmed by the deliberate deception about their condition. It was not just that it involved, first, a lack of informed consent (disrespect for persons), second, a pernicious racial or racist bias (injustice), and third, a failure to minimize possible harms and provide beneficent treatment - bad enough as that is. Several participants were actively prevented from accessing syphilis treatment programs and thus quite directly harmed (Jones 1981: 177).

All this is of course to some extent a question of how to divide the issues between beneficence and nonmaleficence. $P B E$ list prevention and removal of harm under the principle of beneficence. Only the direct infliction of evil or harm falls under the principle of nonmaleficence. This obviously has a certain support in the common morality. Most people believe that a fundamental asymmetry exists between these two types of moral demands. As some of the famous "sacrificing one to save others" examples show, it is not easy to reduce one type to the other. ${ }^{1}$ There are several possible reasons for this. I would like (briefly) to point out two.

First, as Beauchamp and Childress also point out, rules of nonmaleficence are negative and impartial, i.e., we can fulfill them simply by not committing certain acts and they apply equally no matter our relation to the potential victim. Rules of beneficence, on the contrary require positive actions and can often (and sometimes should) be applied partially depending on our relationships with the potential beneficiary.

Second, in cases of sacrificing one to save others, even if we produce some good by inflicting evil or harm, we still need to be "guided by evil" (see Nagel 1986: 181f) we need to direct our actions in ways that we know will harm another person. Regardless of whether we think that such an action can sometimes (in exceptional circumstances) be morally justified, it seems clear that it is categorically different from cases in which we neglectfully fail to prevent or remove evil or harm. Bad as such omissions often are, they normally do not involve this kind of schizophrenic intention.

$P B E$ 's division between nonmaleficence and beneficence is thus not without foundation. Even so, it is not entirely obvious that it gives a perfect reflection of the common morality. At least in some contexts it seems to me clear that the most important distinction is between harm (in general) and benefits and consequently, between rules of non-infliction, prevention, and removal of harm on the one hand, and rules of promoting the good/producing benefits on the other. Many philosophers treat harms and benefits as comparative and symmetrical, as if they were on a scale with positive and negative numbers. Moving up the scale is to be benefitted and moving down the scale is to be harmed. However, this is at odds with the phenomenology of harms and benefits. As pointed out by Seana Shiffrin, a characteristic of enduring harm is that it creates a significant conflict between a person's will and her experience: 
Although harms differ from one another in various ways, all have in common that they render agents or a significant or close aspect of their lived experience like that of an endurer as opposed to that of an active agent, genuinely engaged with her circumstances, who selects, or endorses and identifies with, the main components of her life (Shiffrin 1999: 123).

A characteristic of "pure" benefits, i.e., benefits that do not also involve removal or prevention of harm, is that their absence does not produce the same kind of significant conflict between the person's will and her experience. It just sounds weird to say that absence of a certain good (even a major good) is something a person has to endure or suffer. Shiffrin argues (I think convincingly) that due to this difference there is a moral asymmetry "between harm bestowed to prevent harm and harm bestowed to confer a pure benefit" (Shiffrin 1999: 128). For example, breaking a person's arm as a necessary means to rescue him from mortal danger is clearly morally justified. In contrast, breaking his arm would not be justified (at least not clearly) in an attempt to bestow a pure benefit, even a very significant one. We can largely explain this asymmetry by another characteristic of benefits: if unsought, i.e., merely bestowed on us, benefits "are not as good as benefits that the recipient has chosen to pursue and has succeeded in obtaining" (Velleman 2008: 248). It is much more obvious that we should always accept and welcome other people's attempts to protect us from harm than their (well-meaning) attempts to bestow benefits on us.

The implication for $P B E$ 's division of nonmaleficence and beneficence seems to me to be this: By lumping together the prevention and removal of harm with promotion of the good under the principle of beneficence, Beauchamp and Childress concur with the problematic comparative and symmetrical view. I think this lends undue support to their denial that obligations of nonmaleficence are usually more stringent than obligations of beneficence (Beauchamp \& Childress 2013: 151f). It is significant that the counterexamples they produce are about inflicting harm as a means to prevent greater harms rather than as a means to produce a benefit. ${ }^{2}$

My motivation for presenting these substantial controversies is twofold. On the one hand, they lend support to $P B E$ 's clear distinction between beneficence and nonmaleficence, instead of understanding them as aspects of a unitary principle as in $B R$. On the other hand, they open up the possibility that an alternative distinction is sometimes more significant: the distinction between harms and benefits. I am thus not entirely convinced that $P B E$ 's distinction should be the definitive one. I will return to the important asymmetry considerations when discussing "procreative beneficence" below.

\section{From persons to autonomy}

The other difference between the principles of $B R$ and $P B E$ is related to the first. On the face of it, "respect for persons" looks like a much broader concern than "respect for autonomy". However, this is actually not the case in $B R$ :

Respect for persons incorporates at least two basic ethical convictions: first, that individuals should be treated as autonomous agents, and second, that persons with diminished autonomy are entitled to protection (National Commission 1978: 4).

The second conviction is arguably covered by the principle of nonmaleficence in PBE, in which case all (both) aspects of respect for persons are well covered. 
Nevertheless, this is a point where approaches to bioethics based on relational ethics or ethics of care have criticized both $B R$ and $P B E$. One point of critique is that we owe persons more than just respect for their autonomy, e.g., respect for and protection of their personal integrity and personal dignity (Rendtorff \& Kemp 2000).

As a practical example of the relevance of such considerations, consider palliative and hospice care where these principles arguably play a central role (Nelson 2003, Ryndes \& Emanuel 2003). Good hospice care aims at establishing an open and stable environment in order for the patient to retain her social integrity, e.g., in terms of meaningful time together with family and friends. The threat of physical, mental, and social disintegration experienced by many terminal patients is not only about loss of autonomy understood as self-determination and self-control, even if respect for autonomy may very well be instrumental for protecting the person's integrity. It seems reasonable to claim that concern for integrity should sometimes be a more basic consideration than respect for autonomy.

Recognition and protection of dignity is another prevalent concern here. Ethical guidelines for hospice care invariably emphasize the importance of treating each and every dying person as irreplaceable and unique, not just a case or a task to be solved as efficiently as possible in order to make hospice beds available for more needy patients. Thus, a possible strength of an expanded principle of respect for persons is that it provides a justification for the claim that patients with diminished capacity for autonomy are still owed the same level of protection: out of concern for their integrity and in recognition of their dignity.

The concept of human dignity may seem hopelessly vague and this has led many bioethicists to a rather defeatist attitude. ${ }^{3}$ It may be relevant to point out that the concept of autonomy is not exactly clear and distinct either, at least not absent serious philosophical analysis. There is a certain tendency in many health care systems to understand patients as units in a system of hospital productivity. This typically involves disregard for autonomy, which seems to me to be a symptom of a deeper problem, namely that such reduction is an indignity, since it treats the patient as a kind of commodity or production item and thus disregards the patient's basic human worth. ${ }^{4}$

Beauchamp and Childress could of course argue that the principle of beneficence covers such considerations. After all, physical and social integrity, and being treated as a person rather than an item or a task is in the best interest of the patient. The main reason to be skeptical about such a proposal is analogous to the reasons to insist on respect for autonomy as an independent principle: You want to be respected as a person with values, hopes, dreams, and attachments, not just treated "beneficently" as a container of miscellaneous interests.

\section{Principles in reproductive ethics}

So much for the discussion of $P B E$ 's version of principlism. I now turn to the debate about procreative obligations in reproductive ethics. I mentioned at the outset that this debate is nearly absent in $P B E$. At first glance, it seems that $P B E$ 's principles are nonetheless well proven in reproductive ethics. The overall reproductive ethics debate apparently maps quite neatly onto the principlist framework. There are straightforward questions to ask and distinct debates related to all four principles. More than that: There seem to be no substantial debates that center on principles 
presenting an alternative to $P B E$. In this section, I will give a brief overview of some influential contributions.

\section{Respect for Procreative Autonomy}

The expanding range of procreative choices due to biotechnology would seem to involve an enhancement of parental autonomy. What used to be results of chance and luck will increasingly become matters of choice. Whether the availability of such choices actually increases autonomy turns out to be a matter of controversy, however. To be presented with vast amounts of information about risks, chances and opportunities for interventions and manipulations may lead to an overload in which genuine autonomy may in fact be compromised. The context of choice may be biased towards certain options being the rational or responsible ones, so that the choice may not be that free after all. People grappling with such issues will find invaluable resources for analysis and qualified solutions in $P B E$.

The same goes for classical questions about parental autonomy versus the autonomy of the "person in prospect", e.g., the tension between parents' freedom to select for and against certain traits and capacities on the one hand and claims about the child's best interest, autonomy and "right to an open future" on the other (Feinberg 1980, Kass 2003). On closer inspection, however, it seems that the particular problem of parental choices about future people does move beyond the field covered by $P B E$. According to Jürgen Habermas, procreative choices potentially put future autonomy in jeopardy in two novel ways. First, an obstacle for authentic responsibility for self arises if a person's prospects, potentials, and capabilities turn out to be the result of a detailed, instrumentalist design by parents, genetic consultants or others. Second, the inbuilt inequality between generations of such an arrangement seems to enhance the autonomy of the creator-generation at the cost of the created generation (Habermas 2001). Such objections to unrestrained parental choice are nevertheless normally brought forward on the background assumption that procreative autonomy should be respected (ceteris paribus). People should be free to make their own choices about how and when to procreate, which values and goals to pursue in raising a family and so on.

\section{Procreative Justice}

The principle of justice has perhaps been the one least utilized in reproductive ethics. Most bioethicists seem to prefer alternative principles to capture considerations about the ethically right way for prospective parents to relate to their offspring. The chapter on the principle of justice in $P B E$ is mainly concerned with questions of fairness and entitlements concerning allocation of and access to health care resources, questions that do not relate directly to procreative choices per se. On the other hand, procreative decisions do raise obvious questions about the just distribution of risks and benefits and about equal status between generations (Habermas 2001). Some of the considerations about vulnerability and exploitation also seem to have an obvious bearing on prospective parents' obligations to their offspring.

Jeffrey Reiman (2007: 81) has argued that intentionally bringing disabled people into being violates their right to a normal level of functioning. He argues (plausibly) that such a right would be an outcome of Rawls' "original position" (Rawls 1971). What would be considered important in the original position are the personal and 
social properties of persons (their luck in the genetic and social lottery), not which particular individuals they are (which is hidden by the veil of ignorance) (Reiman 2007: 85f.). In the next section, I will come back to a recent argument about wronging future children that may be understood in terms of justice or fairness.

\section{Procreative Beneficence}

It is obvious that procreative choices involve considerations about beneficence. Most parents are strongly preoccupied with the prospective child's future well-being. We want the best for our children. According to Julian Savulescu, such considerations imply a principle of procreative beneficence. In its original formulation, it read like this:

Couples (or single reproducers) should select the child, of the possible children they could have, who is expected to have the best life, or at least as good a life as the others, based on the relevant, available information (Savulescu 2001:415).

This is an extreme version of such a principle - it is in effect a principle of procreative perfectionism. We will see in the next section that there are a number of relevant objections to such a principle, at least as a sovereign or dominant one. Savulescu's principle also reflects a well-known tension in the notion of beneficence: exactly whom are we supposed to benefit - individuals or collectives? Moral philosophers working within an ethics of care or relational ethics (e.g., Noddings 1995, Gilligan 1995) and utilitarians could agree that we should benefit other people. However, it makes quite a difference whether our focus is on the (concrete) other or the (generalized) others. Similarly, the Principle of Procreative Beneficence does not tell us whether we should interpret "best life" as "best for the person whose life it is" or "best for the overall state of the world."

Savulescu's own answer seems to depend on the circumstances. In a subsequent article, he and Kahane lean towards the individualist interpretation since the principle is now formulated in terms of the child "whose life can be expected [...] to go best" (Savulescu \& Kahane 2009: 274, emphasis mine). The authors make it plain that the aim should be the child who will enjoy the highest possible level of well-being. In other works, however, Savulescu's focus is on overall benefits to society. This is the case in his defense of "moral enhancement," where genetic selection and genetic modification should aim at creating morally better people in order to avoid social problems like xenophobia, crime, poverty and terrorism. All such problems, it is argued, could be remedied by modifications in the human genome (Persson \& Savulescu 2008, 2010; for a forceful critique see Sparrow 2014). This reading turns procreative beneficence into a principle of "procreative altruism" (Douglas \& Devolder 2013). According to this principle, selection need not necessarily be beneficial for the selected child (Elster 2011). Given the seriousness of the problems allegedly solved by moral and cognitive enhancement, this view also seems to weigh strongly against procreative autonomy.

Common to both interpretations is that they leave little if any room for procreative autonomy. As pointed out by Rob Sparrow, the principle of procreative beneficence seems to lead to rather totalitarian conclusions:

"Best" is not an idea which allows room for pluralism. Thus if we could identify an embryo which had the best possible genetics, it appears that all prospective parents 
would be obligated to implant clones of this embryo. This vision of a world of identical "perfect babies" looks disturbingly similar to that which motivated the "old eugenics" of the 1930s (Sparrow 2007, 54).

Savulescu has tried to meet this objection by formulating his principle in a watered down version. Reproducers now have merely "a significant moral reason," and not an obligation, to select the best possible child (Savulescu \& Kahane 2009: 274). This "significant moral reason" can (in principle) be superseded by other reasons including "the interests of parents or reproducers" (Savulescu 2007: 286). The cost of this modification is obviously that the all-things-considered implications of the Principle of Procreative Beneficence become rather vague. ${ }^{5}$

\section{Procreative Nonmaleficence}

A number of authors have argued that the principle of nonmaleficence would serve us better if we want procreative obligations to be more stringent and well-founded. There are entirely reasonable (even classical Millian) restrictions on reproductive autonomy based on the principle of procreative non-maleficence. What makes them reasonable is that we are more confident about the implications of the principle of non-maleficence than about the implications of the principle of beneficence. The ways we can harm people are relatively distinct and well known from an impartial perspective. The implications of the principle of beneficence, however, are far fuzzier and more open-ended. The questions concerning whether disabilities in general or certain disabilities in particular constitute a "negative difference maker" for wellbeing are already pretty complex. I think it is fair to say that matters get a lot more complicated when we start contemplating which positive traits would maximize an individual's well-being (Parker 2007, Barnes 2009, Lillehammer 2009). An obvious explanation why matters get more complicated is that candidate traits for maximal well-being are strongly dependent on the background conception of well-being, e.g., hedonist, preference-based or objective (see Griffin 1986). Furthermore, we would normally have to possess substantial insight into the particular nature of the individual's situation to get a firm grasp of the implications of procreative beneficence, i.e., we would have to know quite a lot about the particular person's preferences, social circumstances, attachments, values and so on. In preconception scenarios, this is by definition beyond our grasp and therefore - to borrow a formulation by Jonathan Glover - we enter a space "where only a monster of selfconfidence would come up with an easy judgment" (Glover 2006: 58).

In cases of severe disability, we seem to be on much firmer ground. We are normally not in doubt as to whether cerebral palsy or deafness are harmful conditions that we ought to remedy if we can and that it would be morally wrong to cause such harms to others. However, in procreation scenarios, these straightforward claims become dramatically harder to make due to the so-called non-identity problem (NIP). In the next section, I will explore as briefly as I can how the NIP affects the principle of procreative nonmaleficence. The purpose is not to come up with a novel solution to the NIP but to extract some possible lessons for principlism.

\section{Non-identity and "Wrongful Disability"}

That parents should not make choices that damage or disable their future child seems to be a straightforward application of the principle of nonmaleficence. If heavy 
smoking or drinking during pregnancy involves significant risks of future suffering for the child then such behavior is clearly morally wrong. In such cases, however, there is a personal identity of the people affected by the alternative behaviors (e.g., smoking vs. not smoking). What is involved here are identity considerations. However, procreative choices typically involve the kind of non-identity considerations introduced by Gregory Kavka (1982) and most famously developed by Derek Parfit (1984: Ch 16).

In such cases, the choice is not between an identical individual with or without disability but between different (non-identical) individuals with or without disability. For example, if a woman, Anne, knows that becoming pregnant at a specific moment will result in a child, Beatrice, with a serious disability, it seems obvious that she has strong reasons to choose to become pregnant later if the result will be a "normal," i.e., non-disabled, child. Now, the problem is that these reasons do not seem to relate to Beatrice. For her, the alternative to being born disabled would be not to be born at all. Since, by hypothesis, her life is well worth living despite her disability she is no worse off by being born disabled as compared to the alternative, which is non-existence. This is how non-identity considerations lead to the non-identity problem:

According to the NIP, even parents who go out of their way to deliberately and maliciously conceive a disabled child have not harmed their child since, so long as their child's life is worth living, the child has not been harmed by her parents' procreative activity (Weinberg 2002, 407).

Contrary to "wrongful life" cases, it seems that Beatrice would not have a case against her parents or other caretakers, even if they had decided to bring her into the world just for the amusement of seeing her struggle with her disability. To put it in the crudest way, imagine Anne arguing like this: "Yes, I decided that you should be born with these serious disabilities just for the fun of it. But since you would not have been born had I decided to have a healthy child instead of you, you cannot really blame me for anything!"

An example by Kavka takes the argument to an even more radical extreme (Kavka 1082: 100ff). Imagine a couple who originally decided not to have any children. However, due to a very lucrative offer from a slave owner, they decide to make a binding contract to give birth to a child whom they sell into slavery for a period of twelve years. Here again, the alternative is non-existence. Let us assume that the person will nonetheless find her life to be worth living after enduring her twelve years as a slave. Even so, we may find the claim that there was "no harm done" extremely implausible. There is broad agreement that these are cases of wrongful disability, i.e., disability caused by a wrongful act (Roberts 2009). It is just that there is no straightforward accounting of exactly what makes it wrongful.

The NIP has proved itself to be an unusually fertile and unusually challenging problem. It has provoked an enormous amount of debate and research. A scholarly work on reproductive ethics would certainly ignore it at its own peril. I cannot do justice to the debate within the confines of this article, but a selection of attempts to solve the NIP will, I think, prove relevant for two questions concerning principlism. One involves the interpretations of the principle of nonmaleficence. The other concerns the question of which principle provides the best analytical framework for explaining specific kinds of wrongdoing (and by implication ethically justified acts). 


\section{Non-identity and Harm}

One (possible) solution to the NIP is simply to accept that there are no personaffecting reasons against selecting for disability or slavery. The wrongness of such acts is due to an 'impersonal harm' either in a very weak sense, by bringing about a worse state of the world or a bit more concretely, by imposing burdens on society at large, e.g., by bringing people with disabilities into it. According to this view, however, no special moral obligations can be said to exist towards the prospective child as a person. Matti Häyry has for example argued that the prospective child is not a stakeholder at all in non-identity scenarios. The relevant stakeholders are only the prospective parents and society in general:

The real clash occurs between the family's interest to have the kind of child they prefer, and society's claim that the production of yet another individual with special needs will place a burden on scarce resources (Häyry 2004: 511).

You do not deprive this individual of anything by selecting a severely defective embryo for the fun of it. Therefore, any moral objection would have to be an objection against putting extra burdens on society in general.

The problem with this suggestion is that it does not capture the intuitive wrongness of Anne's getting pregnant now rather than later. The term 'impersonal harm' is misleading here because it gives the impression that nobody is suffering from our choice of bringing about a disabled person. However, if disabled persons did not generally suffer because of their disabilities then they would (or should) not count as disabilities. We can say that a disability is bad for the person even if it may not be worse for the person to be brought into being as a disabled person (since the alternative was not to be brought into being at all). Intuitively, it seems (ceteris paribus) morally wrong to choose something that is a burden for someone, and that could still be the case in non-identity scenarios.

A more plausible suggestion would be to establish person-affecting reasons by revising the standard interpretation of nonmaleficence. According to the standard interpretation (taken for granted in non-identity considerations), a necessary condition of harm is that the harmed person is made worse off. Of course this is the case in normal situations, but Elisabeth Harman (2004) has argued (I think convincingly) that causing someone to be in a bad state can in itself be a sufficient condition of harm. In non-identity scenarios, the normal conjunction of causing harm and making someone worse off no longer holds, but 'merely' causing someone to be in a bad state still seems prima facie wrong and wrong due to the impact on the person in question. Harman's view is well in line with Shiffrin's point that what constitutes harm is not about comparisons but about victimization. The moral problem with selecting for disability, then, is that a person is made a victim of the choices we have made. If we have obligations in such instances it is not primarily because we have an obligation to optimize the state of the world but rather, in the words of Robert Sparrow, because "the results of our decisions will be sentient entities who will have to live with them" (Sparrow 2007: 46). Derek Parfit, in a posthumous article, suggests a concept of intrinsic harm here (as opposed to comparative harms):

We are merely claiming that being in a state that is bad is worse than not being in any bad state. Having fifty years of suffering is intrinsically bad, and such badness doesn't have to involve being worse than some other state that either Sam [the 
person enduring fifty years of suffering], or we, might have been in. All the badness of Sam's suffering would be had by this suffering. That is what makes such badness intrinsic rather than comparative (Parfit 2017: 133).

A more radical solution is to move beyond the principle of nonmaleficence rather than just to revise it. Some writers have approached the problem from a more Kantian or contractualist perspective (Finneron-Burns 2016, Vrousalis 2013, Weinberg 2008). The term "contractualism" can be somewhat misleading since it seems to imply rather formal and rationalized relations between actual people. The main point, however, is to insist on relations based on mutuality and equal worth. A contractualist, for example, would interpret the wrongness of the slave child case in terms of disrespect rather than harm. It seems quite plausible that one would object to such treatment in terms other than harm and frustration of interests. What is objectionable is the lack of respect for the future child as a possible member of a Kingdom of Ends, a person equal in dignity and rights (Kant 1996). Nicholas Vrousalis points out that what is at stake is "how individuals are approached and treated, rather than (just) about how they fare" (Vrousalis 2013: 602).

Of course, prospective parents cannot literally make a contractual arrangement with their future child. The good news is that contractualism does not operate with such explicit contracts. In Thomas Scanlon's contractualism, for example, the test of a principle (e.g., a principle that allows bringing a slave child into the world for economic gain) is whether anyone would reasonably reject it. I do not think it takes much imagination to see that one would object to disrespectful attitudes, even if such attitudes were a precondition for one's existence. Accepting such a contract would involve "acceptance" with the same merit as giving in to blackmail. The significance of the slave child case is not that the person in question has a life worth living (all things considered) but rather that "another's humanity fails to intrude into the space of the procreator's deliberations as an authoritative (and therefore exclusionary) claim" (Vrousalis 2013: 600).

\section{Conclusion: Lessons for Principlism}

So far so good. The principles of $P B E$ have accomplished their mission of providing "an analytical framework [...] that [is] a suitable starting point for biomedical ethics" (Beauchamp \& Childress 2013: 12). If that were the whole story, however, many critics of principlism would feel confirmed in their objection that the principles are "nothing more than mere names for a collection of sometimes superficially related matters for consideration when dealing with a moral problem" (Clouser \& Gert 1990: 219).

The successive editions of $P B E$ have gradually substantiated the "analytical framework" in two dimensions. One aspect concerns the substance of the principles. Beauchamp \& Childress have been keen to include novel aspects of the principles as a reflection of theoretical critique on the one hand (e.g., from Clouser \& Gert just cited) and new developments in the field of health care on the other.

The other dimension concerns how to handle conflicts among principles. Beauchamp and Childress deny that any general ranking of the principles is plausible. Conflicts between principles in specific cases or types of cases (e.g., cases involving procreative choices) should find closure by specifying and balancing the principles involved (Richardson 2000, Beauchamp \& Childress 2013: 17-24). Balancing involves 
claims about the relative stringency of the principles in the case(s) at hand. For example, it would be plausible to outbalance a minor infraction of autonomy by avoiding considerable harms, whereas the situation can be reversed if we balance autonomous choice concerning central aspects of the person's life-plan against rather trivial harms or benefits. Specification, on the other hand, involves a more narrow and specific formulation of a principle for the purpose of particular types of cases. For example, what does respect for autonomy demand in cases where patients are rewarded for participation in risky experiments? Answering such questions can lead to a formulation of the specific conditions for the meaningful exercise of autonomy. Reflections on conflicts between respect for autonomy and beneficence in cases concerning "medically futile care" may lead to specifications of the principle of beneficence informed by distinctions between the physiological and the existential effect of treatment (Veatch \& Spicer 1992). And so on.

How does reproductive ethics affect principlism along these two dimensions? I will point out four important such impacts based on the considerations above. Note, however, that my claim is not that these considerations are decisive. I am merely demonstrating how such considerations about procreative obligations and nonidentity impact on the general principles if we accept that those considerations have some plausibility.

First, if we accept that the principle of nonmaleficence supports some of the strong objections to Savulescu's principle of procreative beneficence, then there is a strong prima facie case for insisting on nonmaleficence as a freestanding principle the way that Beauchamp and Childress do, in contrast to the Belmont Report. Of course, one may argue that the objections are merely a result of an internal balancing of the nonmaleficence against the beneficence part of the Belmont principle. However, some of the concrete considerations seem to imply something stronger: that the epistemic foundation for what it involves to harm is categorically different from what it means to benefit, especially to benefit maximally. Considerations about procreative obligations and non-identity thus seem to confirm the asymmetry between beneficence and nonmaleficence.

Second, a maximizing conception of beneficence seems to lead to rather worrying eugenic conclusions in the context of procreative ethics. Savulescu's response is to turn the principle of procreative beneficence into a prima facie principle that can be outweighed by other moral reasons. However, Velleman's point (drawing on Shiffrin) that we cannot bestow a maximal level of benefits "from the outside" speaks against that solution. Some good will only be a genuine benefit if it is endorsed, i.e., something that the individual actively chooses and pursues. Moreover, we ought to be cautious about deciding for others exactly which goods are worthy of such endorsement. In the concise formulation of Joseph Raz:

While it is logically impossible to make other people's lives go well, it is possible to try to do so, and such attempts are often disastrous. If the attempt is thorough it is liable to stifle and destroy the victim's chances of having a good life (Raz 1995: 9).

Third, non-identity considerations can contribute significantly to specifications of the principle of nonmaleficence. Instead of concluding from non-identity considerations that nobody is harmed (at least not personally) in wrongful disability cases, Elisabeth Harman and others have argued that they show rather that causing harm must sometimes be specified in a way that does not involve making the harmed 
person worse off (as in paradigmatic cases). Harm can be a matter of being brought into a bad state and we can analyze this in non-comparative ways as suggested by Shiffrin's account.

Fourth, the moral wrongness involved in wrongful disability cases is better captured by a principle of respect for persons with a broader scope than the principle of autonomy in PBE. What is at stake here, according to Vrousalis, Finneron-Burns and others, is a (lack of) respect for persons in prospect as possible members of a Kantian Kingdom of Ends. That is, persons subject to treatment à la Slave Child are not treated as persons equal in dignity and rights, persons worthy of mutual recognition. They are treated as mere instruments in projects where no one cares to imagine what they could reasonably (albeit hypothetically) reject. It may arguably be possible to construct a conception of autonomy (a strongly Kantian one!) substantial enough to capture such considerations. However, as I have indicated, I have more confidence in a broader conception of respect for persons.

It is tempting to think that principles of biomedical ethics should be more rather than less settled after forty years of hard work since $B R$ and seven editions of $P B E$. Already at the turn of the millennium, Henry Richardson, the main champion of the method of specification, thought that we were more or less home free:

[...] the main work that needs to be done in order to achieve progress in bioethics at the present time is in the direction of greater concreteness. The work of abstraction - of crystallizing a few broad principles from out of a mass of messier materials - has already been done by other philosophers and bioethicists (Richardson 2000: 288).

I think this view leans too much towards a top-down approach. Why would we expect the content of the principles to be settled until they have been confronted with all kinds (or at least a very broad range) of concrete biomedical practices and debates? My overall point is that there is a lesson to be learned for principlism when confronted with new practices and new cases. The processes of specification and balancing do not leave the principles unaffected. Nor should they if we take the method of broad reflective equilibrium seriously. ${ }^{6}$

\section{Notes}

${ }^{1}$ See e.g., the example of "Jim and the Indians" in Smart and Williams (1971: 98f.), and the "Arm Twister" in Nagel (1986: 176). For illuminating discussions of a number of other such examples, see Griffin (1996: Ch. VII).

${ }^{2}$ Beauchamp and Childress also come up with an example of inflicting harm in order to produce something closer to a pure benefit: making a donor undergo a somewhat harmful bone marrow transplant in order to increase the recipient's chance of survival. It is far from obvious that morality requires such a procedure. I see this example as another confirmation of Shiffrin's asymmetry claim.

${ }^{3}$ Some bioethicists dismiss the concept of dignity as useless or even stupid (Macklin 2003; Pinker 2008). Beauchamp \& Childress find it "a very unclear notion that moral theory has done little to clarify" (Beauchamp \& Childress 2013: 65). This is striking since the concept of dignity has played a prominent role in the ethical debate about terminal care and end-of-life decisions including physician-assisted death. I cannot 
disentangle these issues here but quite a few philosophers have made decent attempts. For an example of such efforts, see Graaf \& Delden (2009).

${ }^{4}$ Margalit (1996) offers a profound analysis of a broader notion of respect for humans, its implications for social institutions, and the significance of humiliation and other kinds of degradation.

${ }^{5} \mathrm{I}$, for one, would hold a strong interest in making just about any choice not endorsed by Savulescu's principle. I wonder if that would qualify as a defeating reason.

${ }^{6}$ I am deeply indebted to my colleague, Jacob Busch, who developed a number of the more felicitous ideas presented in this article in the course of an earlier (unpublished) project of ours. Thanks are also due to Mette Ebbesen for fruitful discussions and valuable comments.

\section{References}

Barnes E. (2009). Disability, Minority and Difference. Journal of Applied Philosophy 26: 337-355. https://doi.org/10.1111/j.1468-5930.2009.00443.x

Beauchamp, T.L. (2010). Standing on Principles: Collected Essays. Oxford: Oxford UP.

Beauchamp, T.L., Childress, J.F. (2013). Principles of Biomedical Ethics, 7th Ed. New York, Oxford University Press.

Buller, T. (2009). Reproduction, Responsibility, and Rationality. In Simonstein, F. (ed.), Reprogen-Ethics. Dordrecht, Springer. https://doi.org/10.1007/978-90-4812475-6_12

Clouser, K.D., Gert, B. (1990). A Critique of Principlism. Journal of Medicine \& Philosophy 15(2): 219-36. https://doi.org/10.1093/jmp/15.2.219

Clouser, K.D., Gert, B., Culver, C.M. (2006). Bioethics: a systematic approach, 2. ed. New York, Oxford University Press.

Elster, J. (2011). Procreative Beneficence - Cui Bono? Bioethics 25(9): 482-88. https://doi.org/10.1111/j.1467-8519.2009.01794.x

Feinberg, J. (1980). The Child's Right to an Open Future. In Aiken W., LaFollette, H. (eds.), Whose Child? Children's Rights, Parental Authority, and State Power. Totowa, NJ, Littlefield, Adams \& Co.

Finneron-Burns, E. (2016). Contractualism and the Non-Identity Problem. Ethical Theory and Moral Practice 19(5): 1151-1163. https://doi.org/10.1007/s10677016-9723-8

Gilligan, C. (1995). Moral Orientation and Moral Development. In Held, V. (ed.), Justice and Care: Essential Readings in Feminist Ethics. Boulder, CO, Westview Press.

Glover, J. (2006). Choosing Children: Genes, Disability, and Design. Oxford, Oxford University Press. https://doi.org/10.1093/acprof:oso/9780199290925.001.0001

Graaf, R., Delden, J.J.M. (2009). Clarifying Appeals to Dignity in Medical Ethics from an Historical Perspective. Bioethics 23(3): 151-60. https://doi.org/10.1111/ j.1467-8519.2008.00646.x

Griffin, J. (1986). Well-Being: Its Meaning, Measurement, and Moral Importance. Oxford, Oxford University Press.

Griffin, J. (1996). Value Judgment: Improving Our Ethical Beliefs. New York, Oxford UP. 
Habermas, J. (2001). Die Zukunft der menschlichen Natur. Frankfurt am Main, Suhrkamp.

Häyry, M. (2004). There is a difference between selecting a deaf embryo and deafening a hearing child. Journal of Medical Ethics 30: 510-12. https://doi.org/ 10.1136/jme.2002.001891

Jones, J.H. (1981). Bad blood: the Tuskegee syphilis experiment. New York, Free Press. Kant, I. (1996). Practical Philosophy. New York, Cambridge University Press.

Kass, L. (2003). Ageless Bodies, Happy Souls. The New Atlantis 1: 1-19.

Kavka, G. (1982). The Paradox of Future Individuals. Philosophy \& Public Affairs 11(2): 93-112.

Kolthoff, M. (2007). Assisted Reproduction and Primum Non Nocere. Virtual Mentor: AMA Journal of Ethics 9(9): 605-10. https://doi.org/10.1001/ virtualmentor.2007.9.9.ccas2-0709

Lillehammer, H. (2009). Reproduction, Partiality and the Non-Identity Problem. In Roberts, M.A., Wasserman, D.T. (eds.), Harming Future Persons. Dordrecht, Springer: 231-48. https://doi.org/10.1007/978-1-4020-5697-0_11

Macklin, R. (2003). Dignity is a useless concept. British Medical Journal 327: 141920. https://doi.org/10.1136/bmj.327.7429.1419

Margalit, A. (1996). The Decent Society. Cambridge, MA, Harvard University Press.

Nagel, T. (1986). The View from Nowhere. New York, Oxford University Press.

National Commission for the Protection of Human Subjects of Biomedical and Behavioral Research (1978). The Belmont Report. Washington D.C., US Department of Health, Education, and Welfare.

Nelson, H.L. (2003). Pictures of the Person and the Good of Hospice Care. Hastings Center Report Special Supplement 33(2): S18-S19.

Noddings, N. (1995). Caring. In Held, V. (ed.), Justice and Care: Essential Readings in Feminist Ethics. Boulder, CO, Westview Press.

Parfit, D. (1984). Reasons and Persons. Oxford University Press.

Parfit, D. (2017). Future People, the Non-Identity Problem, and Person-Affecting Principles. Philosophy \& Public Affairs 45(2): 118-57. https://doi.org/10.1111/ papa. 12088

Parker M. (2007). The best possible child. Journal of Medical Ethics 33(5): 279-283. https://doi.org/10.1136/jme.2006.018176

Persson, I., Savulescu, J. (2008). The Perils of Cognitive Enhancement and the Urgent Imperative to Enhance the Moral Character of Humanity. Journal of Applied Philosophy 25: 162-77. https://doi.org/10.1111/j.1468-5930.2008.00410.x

Pinker, S. (2008). The Stupidity of Dignity. The New Republic May 28, 2008.

Rawls, J. (1971). A Theory of Justice. Cambridge, MA, Harvard University Press.

Raz, J. (1995). Ethics in the Public Domain. Oxford, Clarendon Press.

Reiman, J. (2007). Being Fair to Future People: The Non-Identity Problem in the Original Position. Philosophy \& Public Affairs 35(1): 69-92. https://doi.org/ 10.1111/j.1088-4963.2007.00099.x

Rendtorff, J.D. \& Kemp, P. (2000). Basic Ethical Principles in European Bioethics and Biolaw, Vol I-II. Copenhagen, Centre for Ethics and Law.

Richardson, H.S. (2000). Specifying, Balancing, and Interpreting Bioethical Principles. Journal of Medicine and Philosophy 25(3): 285-307. https://doi.org/ 10.1076/0360-5310(200006)25:3;1-H;FT285 
Roberts, M. (2009). What is the wrong of wrongful disability? From chance to choice to harms to persons. Law and Philosophy 28: 1-57. https://doi.org/ 10.1007/s10982-008-9031-0

Ryndes, T., Emanuel, L. (2003). Is Discontinuity in Palliative Care a Culpable Act of Omission? Hastings Center Report Special Supplement 33(2): S45-S47.

Savulescu, J. (2001). Procreative Beneficence: Why We Should Select the Best Children. Bioethics 15: 413-26. https://doi.org/10.1111/1467-8519.00251

Savulescu, J. (2007). In Defence of Procreative Beneficence. Journal of Medical Ethics 33(5): 284-288. https://doi.org/10.1136/jme.2006.018184

Savulescu, J., Kahane, G. (2009). The Moral Obligation to Create Children with the Best Chance of the Best Life. Bioethics 23(5): 274-90. https://doi.org/10.1111/ j.1467-8519.2008.00687.x

Scanlon, T. (1998). What We Owe to Each Other. Cambridge MA, Harvard University Press.

Shiffrin, S.V. (1999). Wrongful Life, Procreative Responsibility, and the Significance of Harm. Legal Theory 5(2): 117-48. https://doi.org/10.1017/S1352325299052015

Smart, J.J.C., Williams, B. (1973). Utilitarianism: for \& against. Cambridge: Cambridge University Press. https://doi.org/10.1017/CBO9780511840852

Sparrow, R. (2007). Procreative Beneficence, Obligation, and Eugenics. Genomics, Society and Policy 3(3): 43-59. https://doi.org/10.1186/1746-5354-3-3-43

Sparrow, R. (2014). Unfit for the Future: The Need for Moral Enhancement, by Persson, Ingmar, and Julian Savulescu (Book review). Australasian Journal of Philosophy, 92(2): 404-407. https://doi.org/10.1080/00048402.2013.860180

Steinbock, B., McClamrock, R. (1994). When is Birth Unfair to the Child? Hastings Center Report 24(6): 15-21. https://doi.org/10.2307/3563460

Veatch R.M. and Spicer, C.M. (1992). Medically Futile Care: The Role of the Physician in Setting Limits. American Journal of Law \& Medicine 18(1-2): 15-36. https://doi.org/10.1353/ken.0.0138

Veatch, R.M. (1995). Resolving Conflicts Among Principles: Ranking, Balancing, and Specifying. Kennedy Institute of Ethics Journal 5(3): 199-218.

Velleman, D. (2008). Persons in Prospect. Philosophy \& Public Affairs 36(3): 221-88. https://doi.org/10.1111/j.1088-4963.2008.00139_1.x

Vrousalis, N. (2013). Smuggled into Existence: Nonconsequentialism, Procreation, and Wrongful Disability. Ethical Theory and Moral Practice 16: 589-604. https://doi.org/10.1007/s10677-012-9378-z

Weinberg, R. (2008). Identifying and Dissolving the Non-Identity Problem. Philosophical Studies, 137(1): 3-18. https://doi.org/10.1007/s11098-007-9168-y 